13

\title{
Физический механизм отклонения термоэмиссии катодов от закона Шоттки
}

\author{
(С) В.И. Капустин ${ }^{1}$, И.П Ли ${ }^{2}$, А.В. Шуманов ${ }^{1,2}$ \\ ${ }^{1}$ Московский технологический университет (МИРЭА), \\ ${ }^{2}$ ОАО „Плутон“, Москва \\ E-mail: kapustin@mirea.ru
}

Поступило в Редакцию 6 июня 2017 г.

Отклонение вольт-амперных характеристик материалов катодов СВЧ-приборов от закона Шоттки обусловлено проявлением дрейфа и диффузии кислородных вакансий в кристаллитах оксида бария, являющихся эмиссионноактивным компонентом катодных материалов. Обработка экспериментальных зависимостей с использованием предложенного математического аппарата позволяет найти толщину кристаллитов оксида бария и коэффициент диффузии кислородных вакансий. По величине коэффициента диффузии можно определить наличие микропримесей в оксиде бария, влияющих на его эмиссионные свойства.

\section{DOI: 10.21883/PJTF.2017.19.45076.16906}

Начиная с 1979 г. [1] в литературе появилось множество публикаций, посвященных свойствам „скандатных“ катодов - импрегнированных катодов СВЧ-приборов, содержащих помимо основных компонентов (вольфрам, алюминаты бария-кальция) скандий в виде оксида скандия, гидрида скандия, интерметаллидов скандия и т.д. Плотность тока таких катодов достигает $400 \mathrm{~A} / \mathrm{cm}^{2}$ [2], что превышает плотность тока импрегнированных катодов $\left(15-20 \mathrm{~A} / \mathrm{cm}^{2}\right)$. Однако совершенствование импрегнированных катодов и создание промышленных образцов „скандатных“ катодов сопряжены с трудностью корректного измерения эмиссионных характеристик катодов, в частности величины работы выхода катодных материалов, а также с проблемой спада тока термоэмиссии катодов.

Задача настоящего исследования - разработка теоретической модели, описывающей спад тока термоэмиссии катодов и отклонение 
вольт-амперной характеристики катодов от закона Шоттки, а также экспериментальная проверка предлагаемой модели.

Начальный участок вольт-амперных характеристик катодов описывается известным законом „трех вторых“

$$
I=\beta U^{3 / 2}
$$

где $I$ - плотность тока катода, $U$ - напряжение катод-анод, $\beta-$ константа, называемая первеансом электронного пучка, зависящая от геометрии электронной пушки. Для области насыщения тока термоэмиссии величину плотности тока можно представить в виде

$$
I=A_{0} T^{2} \exp \left[-\frac{\varphi-e\left(\frac{e K_{1} E}{4 \pi \varepsilon_{0}}\right)^{1 / 2}}{k T}\right],
$$

где $k$ - постоянная Больцмана, $T$ - температура, $e-$ заряд электрона, $\varphi$ - работа выхода материала, $\varepsilon_{0}$ - диэлектрическая постоянная, $E$ - напряженность поля в зазоре катод-анод, $K_{1}-$ константа, характеризующая усиление электрического поля у поверхности из-за еe возможной кривизны, $A_{0}-$ постоянная Ричардсона. Зависимость плотности тока термоэмиссии от напряженности электрического поля и называют законом Шоттки.

На рис. 1, $а$ приведена вольт-амперная характеристика импрегнированного катода, выполненного из вольфрамовой губки с пористостью $28 \%$, пропитанной алюминатом состава $2.5 \mathrm{BaO} \cdot 0.4 \mathrm{CaO} \cdot \mathrm{Al}_{2} \mathrm{O}_{3}$, в координатах $\ln I-U^{1 / 2}$. Катод активировался в течение часа при температуре $1150^{\circ} \mathrm{C}$, температура измерения $860^{\circ} \mathrm{C}$. Шаг по напряжению при измерениях составлял $1 \mathrm{~V}$. Область 1 в координатах $I^{2 / 3}-U$ описывается уравнением (1) и имеет вид прямой с тангенсом угла наклона $\beta^{2 / 3}$. Область 2 описывается уравнением (2), при этом экстраполяция ее к напряжению $U=0 \mathrm{~V}$ дает значение тока насыщения термоэмиссии, а наклон экстраполирующей прямой позволяет определить параметр $K_{1}$ с помощью уравнения (2). Область 3 и есть область отклонения тока термоэмиссии от закона Шоттки, причем положение отрезков 4 и 5 , отмечающих переход из области 1 в область 2 и из области 2 в область 3, зависит от морфологии кристаллитов оксида бария, выделяющихся из алюминатов на этапе активирования катода, и от режимов

Письма в ЖТФ, 2017, том 43, вып. 19 

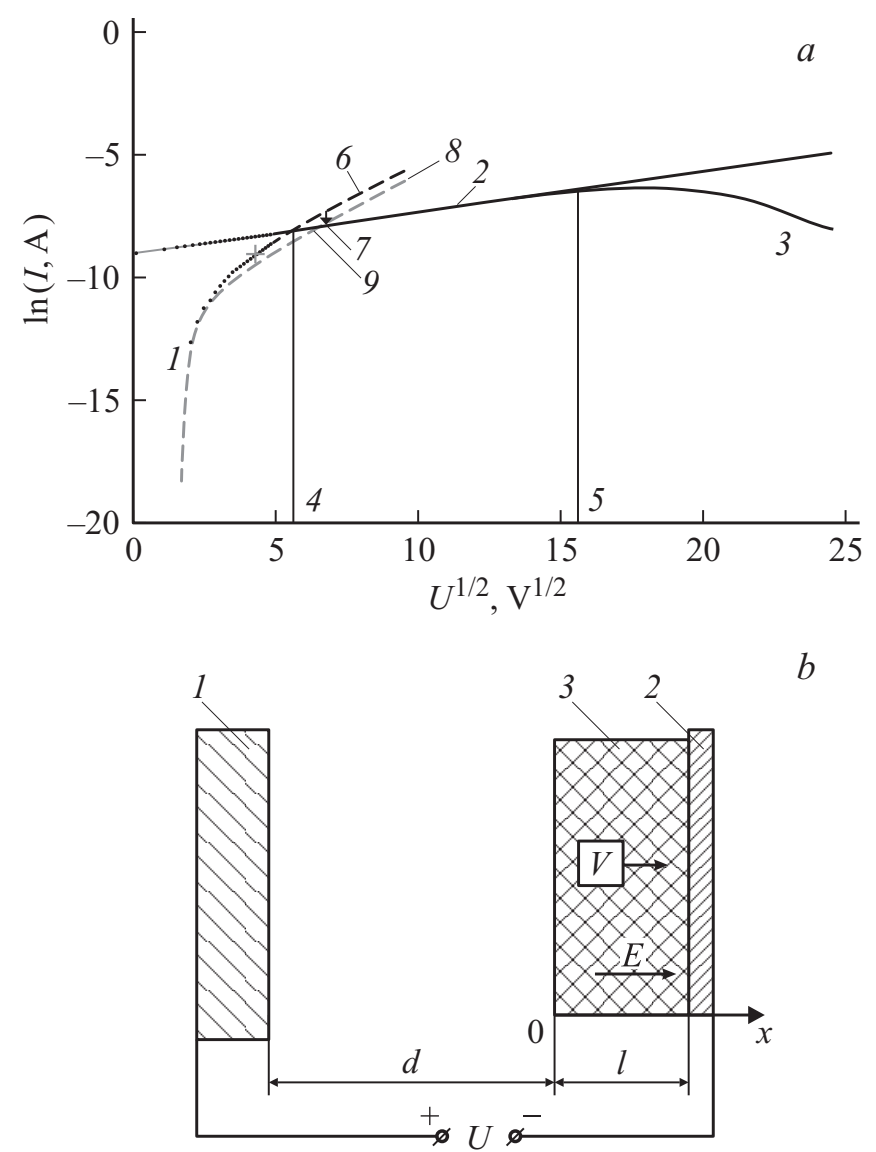

$b$

Рис. 1. Вольт-амперная характеристика импрегнированного катода ( $a$ ) и схема дрейфа и диффузии кислородных вакансий в оксиде бария $(b)$.

активирования и измерений. При этом характер участка 3 зависит от скорости изменения напряжения $U$ при измерениях. При измерениях с шагом более $10 \mathrm{~V}$ выделение участка 2 затруднено. Поэтому в ряде работ были предложены косвенные методы определения величины тока насыщения катода, например по отклонению экспериментальной кривой 
на $10 \%$ от кривой 6 , как показано стрелкой 7 (причем кривая 6 является экстраполяцией кривой 1 в область более высоких напряжений [2]), или по пересечению (точка 9) экспериментальной кривой с кривой 8 , которая в координатах $I^{2 / 3}-U$ имеет тангенс угла наклона, составляющий 0.73 от тангенса угла наклона кривой 1 [3].

Отклонение вольт-амперной характеристики в области 3 от закона Шоттки связано с перераспределением кислородных вакансий в кристаллитах оксида бария в результате диффузии и дрейфа кислородных вакансий в соответствии со схемой, приведенной на рис. $1, b$. На рис. $1, b$ сделаны следующие обозначения: 1 - анод, 2 - металлическая фаза катода, 3 - кристаллит оксида бария толщиной $l$; $d$ - расстояние катод-анод, $U-$ приложенное напряжение, $E-$ напряженность электрического поля в кристаллите оксида бария, $V-$ кислородная вакансия. Реальному дрейфу ионов кислорода в направлении $-x$ в соответствии с полярностью приложенного напряжения отвечает дрейф кислородных вакансий в направлении $+x$.

Для схемы на рис. $1, b$ уравнение диффузии кислородных вакансий с концентрацией $N_{V}(x ; t)$ имеет вид

$$
\frac{\partial N_{V}}{\partial t}=D\left[\frac{\partial^{2} N_{V}}{\partial x^{2}}-\alpha \frac{\partial N_{V}}{\partial x}\right]
$$

причем начальные и граничные условия будут следующими:

$$
N_{V}(x ; t=0)=N_{V 0}, \quad\left(\frac{\partial N_{V}}{\partial x}-\alpha N_{V}\right)_{x=0 ; l}=0 .
$$

С учетом соотношения Эйнштейна для коэффициентов диффузии и дрейфовой подвижности параметр $\alpha$ можно представить в виде

$$
\alpha=\frac{\mu E}{D}=\frac{q E}{k T}=\frac{q U K_{1}}{d \varepsilon k T} .
$$

В соотношениях (3)-(5) $N_{V}$ - концентрация кислородных вакансий, $N_{V 0}-$ начальная концентрация вакансий, $D-$ коэффициент диффузии, $k$ - постоянная Больцмана, $T-$ температура, $\mu-$ дрейфовая подвижность вакансий, $\varepsilon$ - диэлектрическая проницаемость оксида бария, $q$ - эффективный заряд кислородной вакансии.

Письма в ЖТФ, 2017, том 43, вып. 19 
Решением уравнения (3) с граничными и начальными условиями (4) будет

$$
\begin{aligned}
N_{V}= & f(x)+\exp \left[\frac{\alpha x}{2}-\frac{\alpha^{2} D t}{4}\right]\left\{B_{0}+\sum_{n=1}^{\infty} \exp \left[-\frac{\pi^{2} n^{2} D t}{l^{2}}\right]\right. \\
& \left.\times\left[A_{n} \sin \left(\frac{\pi n x}{l}\right)+B_{n} \cos \left(\frac{\pi n x}{l}\right)\right]\right\},
\end{aligned}
$$

где

$$
\begin{gathered}
f(x)=\frac{\alpha l N_{V 0}}{\exp (\alpha l)-1} \exp (\alpha x), \\
B_{0}=\frac{2 N_{V 0}}{\alpha l} \operatorname{sh}\left(\frac{\alpha l}{2}\right)\left[1-\frac{\alpha l}{\exp (\alpha l)-1}\right], \\
A_{n}=N_{V 0} \frac{(-1)^{n} \frac{2}{\pi n} \operatorname{sh}\left(\frac{\alpha l}{2}\right)}{\left(1+\frac{\alpha^{2} l^{2}}{\left.1+\frac{\alpha^{2} l^{2}}{4 \pi^{2} n^{2}}\right)}\left[1+\frac{\alpha l}{\exp (\alpha l)-1}\right],\right.} \\
B_{n}=N_{V 0} \frac{\left.(-1)^{n} \frac{\alpha l}{\pi^{2} n^{2}} \operatorname{sh}^{\frac{\alpha}{2}}\right)}{\left(1+\frac{\alpha^{2} l^{2}}{1+\frac{\alpha^{2} l^{2}}{4 \pi^{2} n^{2}}}\right)}\left[1-\frac{\alpha l}{\exp (\alpha l)-1}\right] .
\end{gathered}
$$

Для области 3 на рис. 1, $a$, как показано далее, параметр $\alpha l \gg 1$, поэтому для $x=0$, логарифмируя уравнение $(6)$, имеем

$$
\begin{aligned}
\ln \left(\frac{N_{V}(t)}{N_{V 0}}\right)= & -\frac{\alpha^{2} D t}{4}+\ln \left(\frac{B_{0}}{N_{V 0}}\right) \\
& +\ln \left[1+\sum_{n=1}^{\infty}\left(\frac{B_{n}}{B_{0}}\right) \exp \left(-\frac{\pi^{2} n^{2} D t}{l^{2}}\right)\right] .
\end{aligned}
$$

В соответствии с $[4,5]$ зависимость плотности тока насыщения с поверхности кристаллитов оксида бария от концентрации кислородных 
Тангенсы углов наклона прямолинейных участков кривой на рис. 2, $b$

\begin{tabular}{l|c|c|c|c|c}
\hline \multirow{2}{*}{$\begin{array}{c}\text { Тангенс угла } \\
\text { наклона }\end{array}$} & \multicolumn{5}{|c}{ Номер линейного участка } \\
\cline { 2 - 6 } & 1 & 2 & 3 & 4 & 5 \\
\hline Выражение & $-\frac{\pi^{2} D}{l^{2}}$ & $-\frac{4 \pi^{2} D}{l^{2}}$ & $-\frac{9 \pi^{2} D}{l^{2}}$ & $-\frac{16 \pi^{2} D}{l^{2}}$ & $-\frac{\alpha^{2} D}{4}$ \\
Значение, $\mathrm{s}^{-1}$ & $-7.57 \cdot 10^{-5}$ & $-2.75 \cdot 10^{-4}$ & $-4.83 \cdot 10^{-4}$ & $-1.12 \cdot 10^{-3}$ & $-5.58 \cdot 10^{-2}$
\end{tabular}

вакансий имеет вид

$$
I=A_{0} T^{2} \frac{\varepsilon \varepsilon_{0} k T N_{V} \exp \left[-\frac{\Delta E_{V}+\chi-2\left(E_{4}-E_{2}\right)}{k T}\right]}{q^{2} N_{S}^{2}\left[1+\frac{a N_{V}}{N_{S}} \exp \left(-\frac{E_{2}-E_{4}}{k T}\right)\right]^{2}} .
$$

В (8) учтено влияние кислородных вакансий на положение уровня Ферми в объеме оксида, искривление энергетических зон у поверхности оксида и связь между концентрациями кислородных вакансий в объеме и на поверхности оксида. В (8) $\chi$ - электронное сродство оксида бария, $\Delta E_{V}$ - глубина уровня кислородных вакансий относительно дна зоны проводимости, $N_{S}$ - поверхностная плотность атомов в оксиде, $a-$ параметр кристаллической решетки оксида, $E_{1}$ - энергия активации перехода атома кислорода из объема оксида в первый монослой, $E_{2}-$ энергия активации обратного перехода, $E_{4}-$ энергия активации перехода атома кислорода из первого монослоя в адсорбированное состояние. Максимум плотности тока достигается при концентрации вакансий, равной

$$
N_{V, \max }=\frac{N_{S}}{a} \exp \left(-\frac{E_{4}-E_{2}}{k T}\right) .
$$

На рис. 2, а приведена экспериментальная зависимость спада тока термоэмиссии импрегнированного катода при температуре $840^{\circ} \mathrm{C}$ и напряжении $U=600 \mathrm{~V}$, а на рис. $2, b-$ та же зависимость в координатах $\ln \left(I / I_{0}\right)-t$. Из соотношения (8) следует, что при $N_{V}<N_{V, \max }$ при уменьшении концентрации кислородных вакансий плотность тока термоэмиссии изменяется прямо пропорционально концентрации кислородных вакансий. На рис. 2, $b$ выделяется пять

2 Письма в ЖТФ, 2017, том 43, вып. 19 

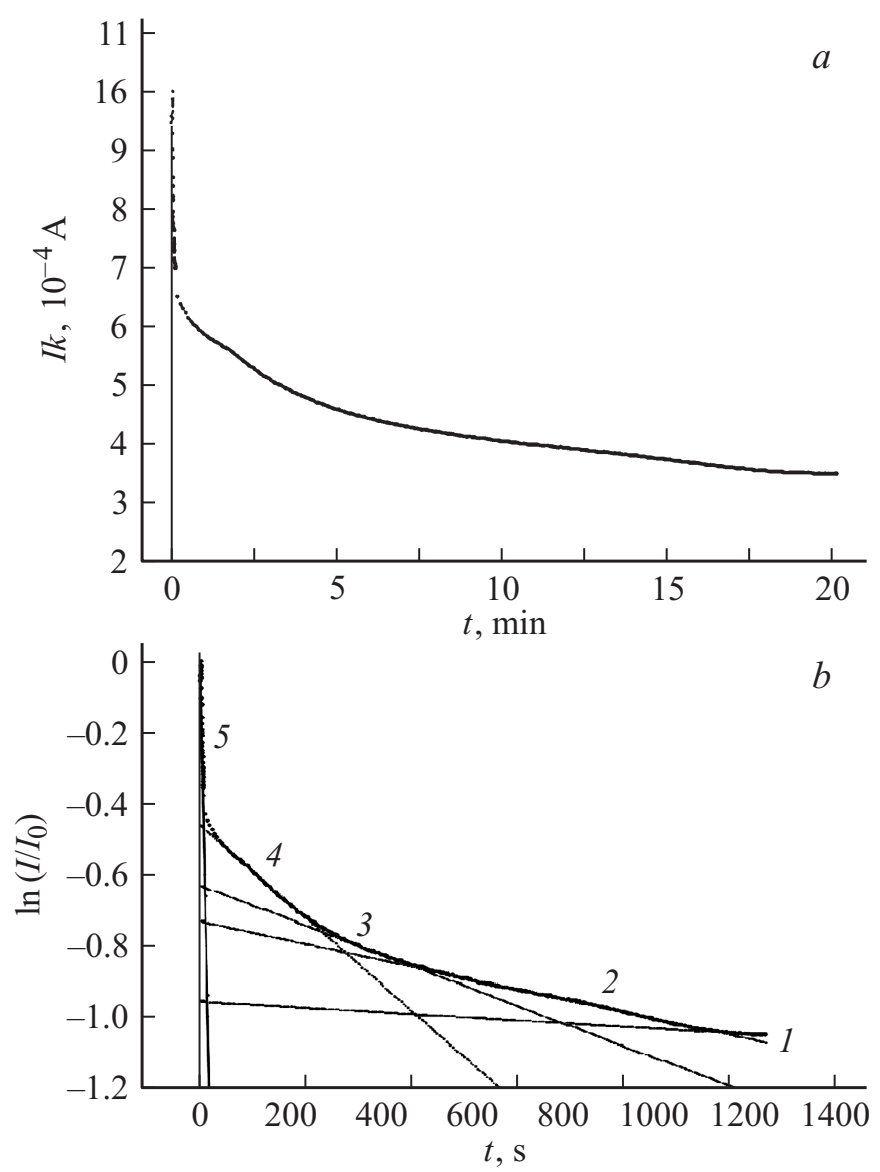

Рис. 2. Экспериментальная кривая спада тока термоэмиссии импрегнированного катода $(a)$ и та же кривая в координатах $\ln \left(I / I_{0}\right)-t(b)$.

прямолинейных участков, тангенсы углов наклона которых следуют из уравнения (7). Их выражения и значения приведены в таблице. Обработка полученных результатов позволила определить значения параметров, фигурирующих в формулах (3)-(5) и характеризующих кислородные вакансии в кристаллитах оксида бария импрегнированного

Письма в ЖТФ, 2017, том 43, вып. 19 


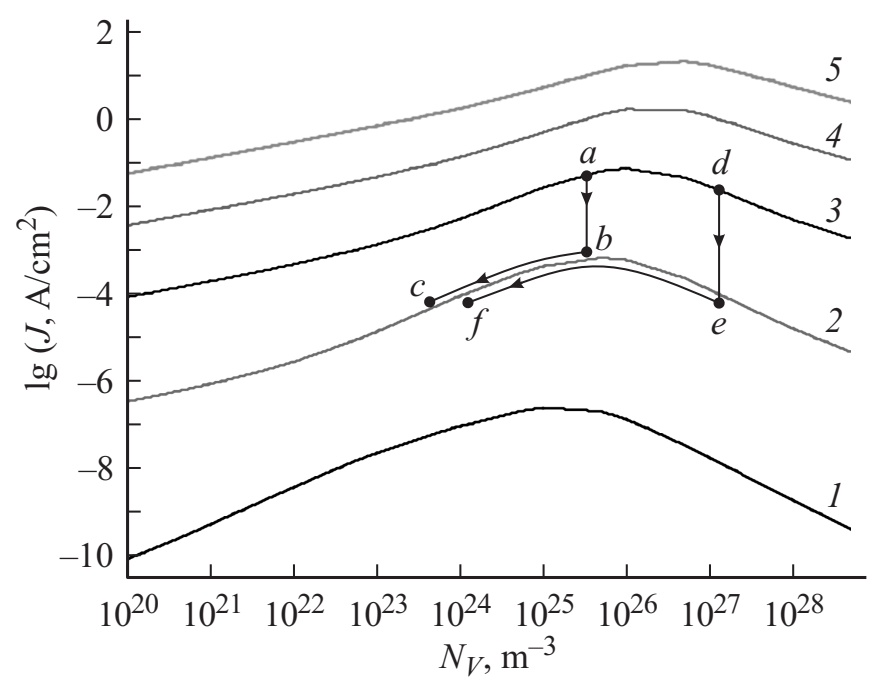

Рис. 3. Расчетная зависимость плотности тока термоэмиссии оксида бария от концентрации кислородных вакансий при температуре 600 (1), 800 (2), 1000 (3), $1200(4), 1400 \mathrm{~K}(5)$.

катода. В частности, $K_{1}=52, \alpha l=181, \alpha=1.61 \cdot 10^{8} \mathrm{~m}^{-1}, l=1.56 \mu \mathrm{m}$, $D=1.65 \cdot 10^{-17} \mathrm{~m}^{2} / \mathrm{s}, \mu=1.72 \cdot 10^{-16} \mathrm{~m}^{2} /(\mathrm{V} \cdot \mathrm{s})$. Значение параметра $q$ для импрегнированного катода (оксид бария, легированный алюминием) взято из работы [6].

На рис. 3 показаны рассчитанные в соответствии с уравнением (8) и приведенные ранее в работе [4] зависимости плотности тока термоэмиссии оксида бария от концентрации кислородных вакансий при различной температуре. На этом же рисунке представлены схемы изменения концентрации кислородных вакансий в приповерхностной области оксида бария при подаче напряжения $U$ для различных начальных условий активирования катода. Точки $a$ и $d-$ состояния после активирования катода до различных значений концентрации кислородных вакансий, точки $b$ и $e-$ состояния в начале измерения спада тока, линии $b-c$ и $e-f-$ пути изменения концентрации вакансий в процессе измерения спада тока термоэмиссии. Отметим, что на пути $e-f$ ток термоэмиссии сначала возрастает, а затем уменьшается,

$2^{*}$ Письма в ЖТФ, 2017, том 43, вып. 19 
что действительно наблюдается экспериментально. Схема на рис. 3 иллюстрирует тот факт, что для достоверного измерения коэффициента диффузии кислородных вакансий и их подвижности, а также толщины оксидного слоя требуется корректное соблюдение начальных условий измерений.

В работе [6] было показано, что микропримеси в кристаллитах оксида бария (кальций, алюминий, вольфрам, скандий) заметно влияют на величину эффективного заряда кислородной вакансии q. Кроме того, растворенные атомы скандия образуют с кислородными вакансиями комплексы, влияющие на величину работы выхода оксида бария. При этом и коэффициент диффузии такого комплекса будет отличаться от коэффициента диффузии кислородной вакансии, так что предложенная экспериментальная методика позволяет эффективно детектировать факт растворения скандия в кристаллитах оксида бария, т.е. факт формирования именно „скандатного“ катода. Предложенный математический аппарат и экспериментальная методика позволяют оптимизировать импульсный режим работы катодов в СВЧ-приборах по параметру спада импульсов тока.

\section{Список литературы}

[1] Van Oostrom A., Augustus L. // Appl. Surf. Sci. 1979. V. 2. N 2. P. 173-186.

[2] Gärtner G., Grittner P., Lydtin H., Ritz A. // Appl. Surf. Sci. 1997. V. 111. P. $11-17$.

[3] Raju R.S, Maloney C.E. // IEEE Trans. Electron. Dev. 1994. V. 41. N 12. P. 2460-2467.

[4] Капустин В.И. // Изв. АН СССР. Сер. физ. 1991. Т. 55. № 12. С. 2455-2458.

[5] Капустин В.И. // Перспективные материалы. 2000. № 2. С. 5-17.

[6] Капустин В.И., Ли И.П., Шуманов А.В. и др. // ЖТФ. 2017. Т. 87. В. 1. C. $105-115$. 